Acknowledgement: I would like to express my very great appreciation to the Universidade de Brasília (UnB) and Hospital Universitário de Brasília (HUB)

Disclosure of Interests: Camila Cadena: None declared, Ana Paula Gomides Grant/research support from: Has received personal support and consulting fees from Pfizer and Janssen, Consultant for: Has received personal support and consulting fees from Pfizer and Janssen, Paid instructor for: Has received personal support and consulting fees from Pfizer and Janssen, Talita Souza: None declared, Luciana Muniz: None declared, Pedro Henrique Almeida: None declared, Sandor Balsamo: None declared, Licia Mota Speakers bureau: Has delivered speeches at events sponsored by AbbVie, Janssen, Pfizer, Roche and UCB. DOI: 10.1136/annrheumdis-2019-eular.5751

\section{FRI0033 QUANTIFERON GOLD-PLUS AND TUBERCULIN SKIN TEST REACTIVITY PREDICTORS IN PATIENTS WITH RHEUMATOID ARTHRITIS}

Juan Pablo Carrizales-Luna ${ }^{1}$, Dionicio Ángel Galarza-Delgado ${ }^{1}$, Luis Adrián Rendón-Pérez ${ }^{2}$, Griselda Serna-Peña ${ }^{1}$, Gisela García-Arellano², Mayra Alexandra Rendón-Medina ${ }^{2}$, Berenice Soto-Monciváis ${ }^{2}$, Leticia Santoyo-Fexas ${ }^{1}$, Juan Manuel Muñoz-Ayala ${ }^{1} .{ }^{1}$ Hospital Universitario Dr José Eleuterio Gonzalez, Rheumatology, Monterrey, Mexico; ${ }^{2}$ Hospital Universitario Dr José Eleuterio Gonzalez, CIPTIR, Monterrey, Mexico

Background: RA patients have high latent tuberculosis(LTBI)prevalence(20$37 \%)^{1}$. In Mexico,ranges from $21.7 \%$ to $31.3 \%$ using tuberculin skin test $(T S T)^{2}$. The methods to detect LTBI are TST and IGRAs. QuantiFERON Gold-Plus (QTF-Plus)uses an antigen tube (TB1) that stimulates CD4+T cells and an additional tube (TB2) that also stimulates CD8+T cells ${ }^{3}$.

Objectives: Determine the LTBI prevalence,variables that predict QTF-Plus and TST results and the concordance between TST and QTF-Plus in RA patients.

Methods: A cross-sectional study in RA patients from the rheumatology department of the University Hospital "José E. González" in Mexico between October 2017 and June 2018. RA patients with ACR/EULAR 2010 classification criteria without a history of tuberculosis (TB) were included.QFT-Plus was performed according to manufacturer instructions. TST was applied with the Mantoux technique; a $>5 \mathrm{~mm}$ cutoff was used. The square chi and Fisher test were used for proportions, Mann-Whitney to compare means,trend analysis using linear trend test and a binary logistic regression model for variables related to positivity to both tests.

Results: We included 111 patients (table 1), the mean age was 51.9 years, $92.3 \%$ were women, disease duration $8.7 \pm 8.8$ years. QTF-Plus was positive in $46(44.6 \%)$ patients. TST was positive in $31(27.9 \%)$ patients. Agreement between tests was $73.7 \%$ (kappa $=0.45, p<0.001)$. The majority of patients were using conventional DMARDs $(86.7 \%)$, none of the patients were using biologic DMARDs. In the linear-to-linear association analysis,there was a trend towards TST negative result with the use of 2DMARDs ( $\mathrm{p}=0.049$ for trend) (figure 1).In the logistic regression model we found a significant relationship between a positive TST active TB exposure(OR $8.5, \mathrm{Cl} \quad 95 \% \quad 1.4-51.7 ; \mathrm{p}=0.01$ )and an inverse relationship between the positive TST and antimalarials (OR 0.11, Cl 95\% 0.001-0.8), none of the variables interfered with QTF-Plus results.

Table 1. Demographic characteristics of RA patients and TST and QTF-Plus comparative analysis.

\begin{tabular}{lccc}
\hline & $\mathrm{N}=111$ & $\begin{array}{c}\text { TST positive } \\
\mathrm{n}=31 / 103^{*}\end{array}$ & $\begin{array}{c}\text { QFT-Plus Positive } \\
\mathrm{n}=46 / 103^{*}\end{array}$ \\
\hline Age, median & $51.9(18-87)$ & $50.4(29-76)$ & $54.4(18-87)$ \\
Female,\% & $105(94.6)$ & $26(83.9)$ & $43(93.5) \dagger$ \\
BCG vaccine, \% & $97(87.6)$ & $28(90.3)$ & $40(87)$ \\
Active TB exposure, \% & $10(9)$ & $5(16.1)$ & $5(10.9) \dagger$ \\
Seropositive, \% & $92(82.9)$ & $25(80.6)$ & $40(87)$ \\
Mean duration, years, SD & $8.7( \pm 8.8)$ & $8.4( \pm 9.2)$ & $8.7( \pm 8.5)$ \\
DAS28-PCR, SD & $2.46( \pm 1.26)$ & $2.30( \pm 1.21)$ & $2.47( \pm 1.30)$ \\
Prednisone use, \% & $60(54.1)$ & $14(45.2)$ & $22(47.8)$ \\
Prednisone, mean dosis, SD & $6.8( \pm 6.9)$ & $4.6( \pm 2.2)$ & $5.3( \pm 3.1)$ \\
DMARDs monotherapy, \% & $42(37.8)$ & $15(48.4)$ & $19(41.3)$ \\
DMARDs double therapy, \% & $38(34.2)$ & $9(29.9)$ & $12(26.1)$ \\
DMARDs triple therapy, \% & $17(15.3)$ & $2(6.5)$ & $8(17.4) \dagger$ \\
Methotrexate, \% & $85(76.6)$ & $14(45)$ & $18(39.1)$ \\
Leflunomide, \% & $32(28.8)$ & $6(19.4)$ & $9(19.6)$ \\
Sulfasalazine, \% & $24(21.6)$ & $7(22.4)$ & $12(26.1)$ \\
Antimalarials, \% & $28(25.2)$ & $6(2.5)$ & $9(19.6) \dagger$ \\
\hline${ }^{*} 8$ subjects with indeterminate QTF-Plus were excluded from this analysis $\dagger \mathrm{p}<0.05$. These
\end{tabular}

*8 subjects with indeterminate QTF-Plus were excluded from this analysis $\uparrow p<0.05$. These variables were included in the logistic regression.

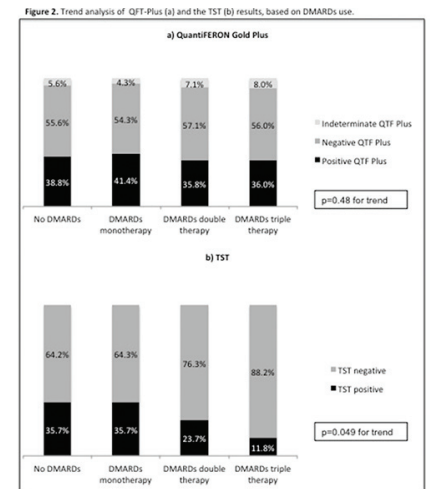

Conclusion: The LTBI prevalence in RA patients in our study is similar to countries with a high TB burden.We recommend considering RA patients as a high-risk population for LTBI.An intermediate agreement between TST and QTF-Plus was found.The use of antimalarials and $\geq$ 2DMARDs influence the TST reactivity, none of the variables altered the QTF-Plus results.Based on the results, we recommend the QuantiFERON Gold Plus over TST for the LTBI screening in RA patients.

\section{REFERENCES}

[1] Sester M,et al.Am J Respir Crit Care Med.2014;190(10):1168-76.

[2] Pérez-Barbosa L,et al.Rheumatol Int.2015;35(9):1555-9.

[3] Takasaki J,et al.J Infect Chemother.2018;24(3):188-92.

Disclosure of Interests: None declared DOI: 10.1136/annrheumdis-2019-eular.5247

\section{FRI0034 A LATIN-AMERICAN PREVENTIVE CARDIO-RHEUMA CLINIC: A CASE-CONTROL STUDY}

Dionicio Ángel Galarza-Delgado ${ }^{1}$, José Ramón Azpiri-López ${ }^{2}$, Iris Jazmin ColungaPedraza $^{1}$, Marielva Castro-González ${ }^{1}$, Karla Paola Cuéllar-Calderón ${ }^{1}$, Ileana Cecilia Reynosa-Silva ${ }^{1}$, Carolina Marlene Martínez-Flores ${ }^{2}$, Guillermo Contreras ${ }^{2}$, Cinthia Yaneth Guillen Gutiérrez", Guillermo Elizondo ${ }^{3} .{ }^{1}$ Hospital Universitario "Dr. José Eleuterio González", UANL, Rheumatology, Monterrey, Mexico; ${ }^{2}$ Hospital Universitario "Dr. José Eleuterio González", UANL, Cardiology, Monterrey, Mexico; ${ }^{3}$ Hospital Universitario "Dr. José Eleuterio González", UANL, Radiology, Monterrey, Mexico

Background: It has been described an increased prevalence of cardiovas cular diseases (CVD) in rheumatoid arthritis (RA) patients. When compared with the general population, CVD mortality is $50 \%$ higher in RA (1). It is reported a $35.3 \%$ prevalence of CVD in Latin-American popula tion with RA (2). Cardio-rheuma (CR) clinics were designed to enhance detection, prevention and treatment of CVD in patients with rheumatic conditions. Our clinic located in the University Hospital in Monterrey Mexico, is the first and only established in Latin-America since 2014.

Objectives: To describe the characteristics of patients with RA attending to a Latin-American $\mathrm{CR}$ clinic and compare the findings by carotid ultrasound (US) and echocardiography to controls.

Methods: Cross-sectional, observational, comparative study. RA patients aged 40 to 75 years that fulfilled the 2010 EULAR criteria and matched controls were included. Patients with prior atherosclerotic CVD and overlap syndromes were excluded. Clinical history, blood samples, physical exam, carotid US and echocardiography were performed. Carotid plaque (CP) was defined as a focal narrowing $\geq 0.5 \mathrm{~mm}$ of the surrounding lumen or a carotid intima media thickness (cIMT) $\geq 1.2 \mathrm{~mm}$, and increased cIMT was defined as $\geq 0.9 \mathrm{~mm}$. Transthoracic echocardiogram was performed and reviewed by 2 board-certified cardiologists. Differences were solved by consensus. Categorical variables are expressed as total number (\%), and numerical variables as median (q25-q75). Chi square and Mann-Whitney U-test were used to compare groups and considered significant if $p<0.05$.

Results: A total of 336 RA patients and 144 controls were included (Table 1). Table 2 summarizes echocardiographic and carotid US findings ejection fraction was higher in controls than RA patients, prevalence of bilateral $\mathrm{CP}$ and increased CIMT was significantly higher in RA patients. 
Table 1. Patient characteristics

\begin{tabular}{lccc}
\hline Variable & $\begin{array}{c}\text { RA } \\
(\mathbf{n}=336)\end{array}$ & $\begin{array}{c}\text { Controls } \\
(\mathbf{n}=\mathbf{1 4 4})\end{array}$ & $\boldsymbol{p}$ \\
\hline Age (years), median (q25-q75) & $55.5(48-61)$ & $53(48-58)$ & 0.017 \\
Women, $\mathrm{n}(\%)$ & $311(92.6)$ & $134(93.1)$ & $\mathrm{NS}$ \\
Disease duration (years), median (q25- & $7.8(3.2-15)$ & - & - \\
q75) & & & \\
BMI (kg/m²), median (q25-q75) & $27.6(25.1-$ & $27.8(24.9-$ & $\mathrm{NS}$ \\
& $31.2)$ & $31.5)$ & \\
Diabetes Mellitus, $\mathrm{n}(\%)$ & $47(14)$ & $14(9.7)$ & $\mathrm{NS}$ \\
Dyslipidemia, $\mathrm{n}(\%)$ & $93(27.7)$ & $31(21.5)$ & $\mathrm{NS}$ \\
Hypertension, $\mathrm{n}(\%)$ & $93(27.7)$ & $31(21.5)$ & $\mathrm{NS}$ \\
DAS28-CRP, median (q25-q75) & $3.2(2.1-4.3)$ & - & - \\
Past or current smoker, $\mathrm{n}(\%)$ & $65(19.3)$ & $36(25)$ & $\mathrm{NS}$ \\
Nonsteroidal anti-inflammatory drugs, $\mathrm{n}$ & $90(26.8)$ & - & - \\
(\%) & & & \\
Prednisone, $\mathrm{n}(\%)$ & $195(58)$ & - & - \\
Methotrexate, $\mathrm{n}(\%)$ & $283(84.2)$ & - & - \\
Leflunomide, $\mathrm{n}(\%)$ & $69(20.5)$ & - & - \\
Chloroquine, $\mathrm{n}(\%)$ & $54(16.1)$ & - & - \\
Sulfasalazine, $\mathrm{n}(\%)$ & $59(17.6)$ & - & - \\
Hydroxychloroquine, $\mathrm{n}(\%)$ & $34(10.1)$ & - & - \\
Biologic DMARDs, $\mathrm{n}(\%)$ & $21(6.3)$ & - & - \\
\hline
\end{tabular}

Table 2. Echocardiographic and carotid US findings

\begin{tabular}{lccc}
\hline Echocardiography & RA $(\mathbf{n}=60)$ & Controls $(\mathbf{n}=\mathbf{2 8})$ & $\boldsymbol{p}$ \\
\hline Ejection fraction, median (q25- & $60(56.2-$ & $63(60-69)$ & $\mathbf{0 . 0 0 8}$ \\
q75) & $65.0)$ & & \\
Abnormal LV geometry, $\mathrm{n}(\%)$ & $21(35)$ & $7(25)$ & $\mathrm{NS}$ \\
Abnormal LA geometry, $\mathrm{n}(\%)$ & $6(10)$ & $3(10.7)$ & $\mathrm{NS}$ \\
Carotid US, $\mathbf{n}(\%)$ & $\mathbf{R A}(\mathbf{n = 1 2 8 )}$ & Controls & \\
& & $(\mathbf{n}=\mathbf{1 1 0})$ & \\
CP & $38(29.7)$ & $25(22.7)$ & $\mathrm{NS}$ \\
Increased cIMT & $64(50)$ & $32(29.1)$ & $\mathbf{0 . 0 0 1}$ \\
Unilateral CP & $18(14.1)$ & $17(15.5)$ & $\mathrm{NS}$ \\
Bilateral CP & $20(15.6)$ & $8(7.3)$ & $\mathbf{0 . 0 4 6}$ \\
\hline
\end{tabular}

Conclusion: RA patients from this clinic had lower ejection fraction, more prevalence of cIMT and bilateral CP when compared to controls. It is important that rheumatologists perform a complete evaluation of their patients, in which cardiovascular assessment should be included.

\section{REFERENCES:}

[1] Aviña-Zubieta JA, et al. 2008. Arthritis \& Rheumatism.

[2] Sarmiento-Monroy JC, et al. 2012. Hindawi Publishing Corporation.

Disclosure of Interests: None declared

DOI: 10.1136/annrheumdis-2019-eular.4280

\section{FRI0035 INFLAMMATORY ARTHRITIS INDUCED BY IMMUNE- CHECKPOINT INHIBITORS: RESULTS FROM A COMBINED RHEUMATOLOGY/ONCOLOGY OUTPATIENT CLINIC}

Fulvia Ceccarelli ${ }^{1}$, Andrea Botticelli ${ }^{2}$, Alain Gelibter ${ }^{2}$, llaria Leccese ${ }^{1}$, llaria Zizzari ${ }^{3}$, Grazia Sirgiovanni ${ }^{2}$, Francesca Romana DI Pietro ${ }^{2}$, Ramona Lucchetti ${ }^{1}$, Carlo Perricone ${ }^{1}$, Enrico Cortesi ${ }^{2}$, Marianna Nuti ${ }^{3}$, Fabrizio Conti ${ }^{1}$ Paolo Marchetti' ${ }^{2}$, Guido Valesini ${ }^{1}$. ${ }^{1}$ Sapienza Università di Roma, Sapienza Arthritis Center, Reumatologia, Dipartimento di Medicina Interna e Specialità Mediche, Rome, Italy, ${ }^{2}$ Sapienza Università di Roma, Oncologia Medica B, Rome, Italy, ${ }^{3}$ Sapienza Università di Roma, Experimental Medicine Department, Rome, Italy

Background: Immune checkpoint inhibitors (ICls) has radically changed the oncology field: the blockade of co-stimulatory molecules on $\mathrm{T}$ cells, antigen presenting cells and tumor cells induces unchecked $T$ cell activation with subsequent immune response targeting malignant cells. In the last years, different ICls have been approved for the treatment of several malignancies. The stimulation of the immune response could be associated with the development of immune-related adverse events (irAEs), potentially involving every organ/system (1). Musculo-skeletal manifestations represent one of the most common irAEs developing during ICls treatment: up to $40 \%$ of treated patients could experience arthralgia or arthritis. Moving from these evidences, the role of the rheumatologist became very important in the management of $\mathrm{ICls}$ treated patients (2).

Objectives: To determine the frequency of musculo-skeletal manifestations in patients treated with $\mathrm{ICls}$ in a combined rheumatology/oncology outpatient clinic.

Methods: From January 2015 we organised a rheumatology/oncology combined outpatient clinic: all patients starting an ICls treatment were referred from oncologist to rheumatologist. Data from patients, including demographic features, date of diagnosis, comorbidities and previous and concomitant medications, smoke habit, were collected and registered into a standardized, computerized, electronically filled-in form. All the patients underwent to a physical and laboratory evaluation in order to assess the presence of tender and swollen joints. In case of joint involvement, we assessed disease activity by clinimetric evaluation (DAS28) and ultrasonographic assessment of involved joints (presence of active synovitis as for presence of power Doppler). Moreover, a laboratory evaluation including, ESR, CRP, and autoantibodies (ANA, ACPA, RF) was performed.

Results: Seventy-two patients were evaluated (M/F 48/24, median age 66.0 years, IQR 13.0; median disease duration 7 months, IQR 13.0) Concerning malignant disease, $75.1 \%$ were affected by non-small cell lung cancer, $15.3 \%$ by renal cell carcinoma, $6.9 \%$ by melanoma, $2.7 \%$ by other malignancies; all patients were treated with anti-PD-1, 67 $(93.1 \%)$ with nivolumab and $5(6.9 \%)$ with pembrolizumab. During ICls treatment, 7 patients $(9.7 \%)$ developed clinically evident synovitis (absolute risk: 0.1 ; incidence rate 0.01 patients/month): table 1 reports the main features of these 7 patients. According with ACR/EULAR 2010 criteria, two patients could be classified as affected by rheumatoid arthritis (RA). Six patients $(85.7 \%)$ were treated by prednisone (dosage range 10 $12.5 \mathrm{mg} /$ daily) or NSAIDs, experiencing a rapid, complete and persistent response. Patient 2, due to resistance to prednisone, was treated by methotrexate $10 \mathrm{mg} /$ weekly achieving remission after 6 weeks.

Conclusion: The present study represents the first attempt to apply a multidisciplinary approach involving rheumatologists and oncologists in the evaluation of patients treated with $\mathrm{ICls}$. We found a high absolute risk $(10 \%)$ to develop synovitis in patients treated by ICls. Interestingly, the majority of these patients experienced a clinically evident synovitis promptly responding to glucocorticoids and not requiring further DMARDs treatment. This could suggest a peculiar pathogenesis of such IClsinduced arthritis.

\section{REFERENCES :}

[1] Calabrese L \& Velcheti V, Ann Rheum Diseases 2016; 2. Mooradian MJ et al, Semin Arthritis Rheum 2018

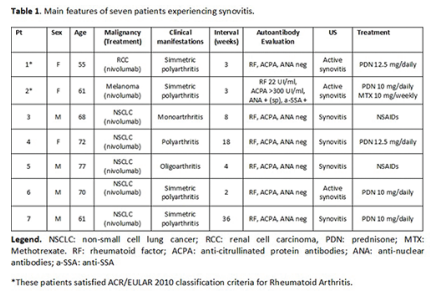

Disclosure of Interests: Fulvia Ceccarelli: None declared, Andrea Botticelli: None declared, Alain Gelibter: None declared, llaria Leccese: None declared, Ilaria Zizzari: None declared, Grazia Sirgiovanni: None declared, Francesca Romana Di Pietro: None declared, Ramona Lucchetti: None declared, Carlo Perricone Speakers bureau: BMS; Lilly, Celgene, Sanofi, Enrico Cortesi: None declared, Marianna Nuti: None declared, fabrizio conti: None declared, Paolo Marchetti: None declared, Guido Valesini: None declared DOI: 10.1136/annrheumdis-2019-eular.7279 